\title{
Zantaz honey "monoflorality": Chemometric applied to the routinely assessed parameters
}

\author{
Youssef Elamine $^{\mathrm{a}, \mathrm{b}}$, Badiâa Lyoussi ${ }^{\mathrm{a}}$, Ofélia Anjos ${ }^{\mathrm{c}, \mathrm{d}, *}$, Leticia M. Estevinho ${ }^{\mathrm{e}}$, Smail Aazza ${ }^{\mathrm{a}, \mathrm{f}}$, \\ Jorge D. Carlier ${ }^{g}$, Maria C. Costa ${ }^{g}$, Maria G. Miguel ${ }^{\mathrm{b}}$ \\ ${ }^{a}$ Laboratory of Physiology-Pharmacology-Environmental Health, Faculty of Sciences Dhar El Mehraz, BP 1796 Atlas, University Sidi Mohamed Ben Abdallah, Fez 30 000, \\ Morocco \\ ${ }^{\mathrm{b}}$ Universidade do Algarve, FCT, MeditBio, Edf 8, Campus de Gambelas, 8005-139, Faro, Portugal \\ ${ }^{\mathrm{c}}$ Instituto Politécnico de Castelo Branco, Castelo Branco, 6001-909, Portugal \\ ${ }^{\mathrm{d}}$ Centro de Estudos Florestais, Instituto Superior de Agronomia, Universidade de Lisboa, Tapada da Ajuda, Lisboa, 1349-017, Portugal \\ e CIMO, Mountain Research Center, Polytechnic Institute of Bragança, Campus Santa Apolónia, 5301-855, Bragança, Portugal \\ ${ }^{\mathrm{f}}$ Laboratory of Phytochemistry, National Agency of Medicinal and Aromatic Plants, BP 159, Taounate, Morocco \\ ${ }^{\mathrm{g}}$ Centro de Ciências do Mar, Universidade do Algarve, FCT, Campus de Gambelas, Faro, 8005-139, Portugal
}

\section{A R T I C L E I N F O}

\section{Keywords:}

Bupleurum spinosum

Monoflorality threshold

Melissopalynology

Principal component analysis

\begin{abstract}
A B S T R A C T
The comparison of Zantaz honey samples harvested in Morocco in two different years was performed through chemometric analysis of routinely assessed parameters. The objective was to study how the pollen profile of this newly reported honey shapes its physicochemical characteristics as well as to determine its monoflorality threshold, which has not yet been defined. The predominance of $B$. spinosum pollen was confirmed in the majority of samples reaching $45 \%$, generally requested for monoflorality declaration. The principal component analysis (PCA) was used for clustering and variables correlations. Pollen qualitative and quantitative differences could discriminate the samples belonging to both seasons when combined with the sugar analysis (59.44\%) better than the combination with physicochemical parameters $(\mathrm{pH}$, acidity, ash content, electrical conductivity and color) (60.62\%). Positive correlation between the presence of B. spinosum pollen and melanoidins, color, fructose, moisture, trehalose, melezitose, iron, manganese and calcium could be seen. Integrating all the parameters except the pollen data allowed distinguishing two groups with significant differences $(P<0.05)$ in $B$. spinosum representability ( $58 \pm 11.24 \%$ against $40 \pm 15.98 \%$ ). This may suggest that $40 \%$ is the monoflorality threshold of the Moroccan Zantaz honey, although a confirmation with sensorial analysis is required.
\end{abstract}

\section{Introduction}

Chemometrics application to food chemistry parameters is attracting more attention from the scientific community due to its power on the elaboration of conclusions about the traceability (Bertacchini et al., 2013) and the classification/clustering problems (Anjos et al., 2015a; Silva, Gauche, Gonzaga, Costa, \& Fett, 2016). These techniques were previously applied on the analysis of several food products, among which coffee (Briandet, Kemsley, \& Wilson, 1996) and amino acids content in honey (Zhao et al., 2018). Honey does not make an exception; indeed the chemometric tools were not only used as a discriminatory tool between honeys with different geographical (Estevinho, Chambó, Pereira, Carvalho, Alencar, 2016; Karabagias et al., 2017a, 2017b) or botanical origins (Corbella \& Cozzolino, 2006; Devillers, Morlot, Pham-Delègue, \& Doré, 2004; Terrab, Díez, \&
Heridia, 2002) but also as an effective way to detect honeys' adulteration (Wang et al., 2014). Several tools can be employed depending on the study aim, implicating the filtration of the parameters. This parameters' filtration helps choosing the adequate parameters/variables carrying the adequate information as well as the elimination of the "noising" parameters (Bevilacqua, Bucci, Magrì, Magrì, \& Nescatelli, 2013).

Honey monoflorality determination can be done using the combination of pollen spectrum analysis, physicochemical parameters and sensorial qualities (Bogdanov, Ruoff, \& Oddo, 2004). This last step is highly expensive, requiring panels of assessors which go through controlled experimental protocols. The results need to be statistically reproducible to be considered (Piana et al., 2004). In fact, a predictive relationship has been established between physicochemical characteristics and sensory properties (Pestorić et al., 2015), although this should

\footnotetext{
* Corresponding author.Instituto Politécnico de Castelo Branco, Castelo Branco, 6001-909, Portugal

E-mail address: ofelia@ipcb.pt (O. Anjos).
} 
be interpreted cautiously (Estevinho, Chambó, Pereira, De Carvalho, \& De Alencar Arnaut De Toledo, 2016). This relationship can be highlighted by the fact that both sensorial and physicochemical properties are determined by the nectar of the visited melliferous plants. As there is no way to evaluate the nectar delivered by each plant, researchers used to estimate it by using the pollen profiling, or mellissopalynology. The monoflorality threshold, considering a pollen species, is then the percentage above which honey samples becomes governed by the physicochemical and sensorial properties of the corresponding nectar.

Generally, a honey sample is considered to be monofloral, or governed by the physicochemical and sensorial properties of the main nectar, when the pollen of its main originating melliferous plant exceed 45\% (Louveaux, Maurizio, \& Vorwohl, 1978). Two exceptions to this rule can be mentioned: lavender honey, for which the presence of $15 \%$ of lavender pollen is enough to be labelled as monofloral (Estevinho et al., 2016), and chestnut honey which is labelled only when presenting more than $90 \%$ of chestnut pollen (Louveaux et al., 1978). Those exceptions emphasize the importance of establishing a specific threshold for a given honey type, especially when it is newly introduced to the scientific community, which is the case of the Moroccan Zanataz honey. A holistic view needs to be given not only about its characterizing parameters, but on how the pollen profiling shapes them. In other words, at which level the main pollen representability needs to achieve to consider a Zantaz honey sample as monofloral.

In fact, establishing monoflorality threshold for a given honey is not a trivial task. The variability of the contribution of the participating melliferous plants belonging to two different seasons, or geographical regions, is highly influential in shaping the final characteristics of honey samples (Estevinho et al., 2016). The present contribution aimed a second characterization of a new set of the Moroccan Zantaz honey samples known by the prevalence of Bupleurum spinosum pollen exceeding $45 \%$, as a sequence of the previously published study (Elamine et al., 2018). Furthermore, the data of both studies will be integrated using the appropriate multivariate analysis to assess the effect of seasonal variability on the identified pollen species, and how the pollen spectrum correlate the acquired physicochemical characteristics of Zantaz honey samples. In addition, PCA will be applied using all analysed parameters. The pollen profile of the output clusters will be statistically compared in an attempt to determine how the homogeneity of the samples forming each cluster is determined by the presence of $B$. spinosum pollen.

\section{Materials and methods}

\subsection{Sample preparation}

Honey samples $(n=18)$ were purchased from beekeepers, centrifuged and kept under ambient temperature until their use. To strengthen the conclusions of the multivariate analysis section of the present work, the data of the samples $(\mathrm{N}=12)$ published in the previous study (Elamine et al., 2018) was also used.

\subsection{Pollen analysis}

The qualitative and quantitative analysis of pollen spectrum was accomplished following the International Commission for Bee Botany (ICBB) method, as described previously (Louveaux et al., 1978). An optic microscope (Leitz Messtechnik GmbH, Wetzlar, Germany) with $400 \times$ and $1000 \times$ objectives, was used for pollen identification and count. One thousand pollen grains were counted for each sample, and the frequent classes were determined twice. A pollen species was considered dominant, when it represents more than $45 \%$ from the pollen spectrum, secondary with percentage between $16 \%$ and $45 \%$, important minor pollen from 3 to $15 \%$ and minor pollen when it is less than $3 \%$.

\subsection{Acidity, $p H$, conductivity, moisture, color, proline, diastase activity}

Free acidity, lactonic acidity, total acidity, $\mathrm{pH}$, ash content, electrical conductivity, moisture, diastase activity, were assessed following the Harmonized Methods of the International Honey Commission (Bogdanov, 1997, pp. 1-62).

\subsection{Colour and melanoidins}

Colour was determined by measuring the absorbance of aqueous honey solutions $\left(10 \mathrm{~g}\right.$ in $\left.20 \mathrm{~mL} \mathrm{H}_{2} \mathrm{O}\right)$ at $635 \mathrm{~nm}\left(\mathrm{~A}_{635}\right)$ in a Shimadzu spectrophotometer (Naab, Tamame, \& Caccavari, 2008). The mm Pfund values and honey colour were obtained using the following algorithm, $\mathrm{mm}$ Pfund $=-38.7+371.39 \times \mathrm{A}_{635}$. Additionally, honey colour was determined by spectrophotometry by calculating net absorbance $\left(\mathrm{A}_{560^{-}}\right.$ $A_{720}$ ). Melanoidin content was estimated based on the browning index (net absorbance $=\mathrm{A}_{450}-\mathrm{A}_{720}$ ) (Brudzynski \& Miotto, 2011). Spectrophotometric measurements were performed in a $1 \mathrm{~cm}$ quartz cell;

\subsection{Sugars}

The sugar contents were analysed by High Performance Liquid Chromatography (HPLC) with refraction index (IR) detector according the methodology proposed by Bogdanov (1997, pp. 1-62). The HPLC analysis was performed on analytical stainless-steel column, Purospher ${ }^{\circ}$ STAR - NH2 with $4 \mathrm{~mm}$ in diameter, $250 \mathrm{~mm}$ length and with $5 \mathrm{~mm}$ particle size, using a flow rate of $1.3 \mathrm{~mL} / \mathrm{min}$; mobile phase: acetonitrile: water $(80: 20, \mathrm{v} / \mathrm{v})$; column and detector temperature: $30^{\circ} \mathrm{C}$; and sample volume injection of $10 \mathrm{ml}$.

The different sugars (fructose, glucose, sucrose, melezitose, turanose, maltose, xilose, rhamnose, arabinose, melibiose, trehalose and erlose) were identified and quantified by comparison of the retention times and the peak areas of the honey sugars with those of calibration curves of standard sugars. The values expressed in $\mathrm{g} / 100 \mathrm{~g}$ of honey. Retention time (RT), limit of quantification (LQ) of the analysed sugars are illustrated in Table 1.

\subsection{Minerals}

Sample preparation is initiated by calcination of $5 \mathrm{~g}$ honey at $550^{\circ} \mathrm{C}$. After cooling, $5 \mathrm{~mL}$ of $0.1 \mathrm{M}$ nitric acid was added to the ash and the mixture was stirred on a heating plate to almost complete dryness. Then, $10 \mathrm{~mL}$ of the same nitric acid solution was added, and the mixture was brought up to a final volume of $25 \mathrm{~mL}$ with distilled water. Afterwards, $\mathrm{Ca}, \mathrm{Mg}, \mathrm{Mn}, \mathrm{Zn}, \mathrm{Cu}$, and Fe were measured by flame atomic absorption, while $\mathrm{Na}, \mathrm{K}$ by emission spectrometry (air-acetylene) using a novAA 350 (Analytik Jena, Germany). After the determination of mineral concentrations in the prepared solutions, their values were extrapolated to be expressed as $\mathrm{mg} / \mathrm{kg}$ honey.

Table 1

Retention time, limit of quantification of the analysed sugars.

\begin{tabular}{llll}
\hline Analyte & $\mathrm{N}$ & $\mathrm{RT}(\mathrm{min})$ & $\mathrm{LQ}(\mathrm{g} / 100 \mathrm{~g})$ \\
\hline Ramnose & 3 & 3.83 & 0.17 \\
Xylose & 1 & 4.24 & 0.87 \\
Arabinose & 6 & 4.96 & 0.13 \\
Fructose & 31 & 5.46 & 0.77 \\
Glucose & 31 & 6.42 & 1.61 \\
Sucrose & 7 & 9.45 & 0.23 \\
Turanose & 31 & 10.45 & 0.06 \\
Maltose & 31 & 11.55 & 0.66 \\
Melibiose & 31 & 12.69 & 0.12 \\
Trehalose & 31 & 15.27 & 0.16 \\
Melezitose & 13 & 18.32 & 0.08 \\
Erlose & 6 & 22.60 & 0.16 \\
\hline
\end{tabular}




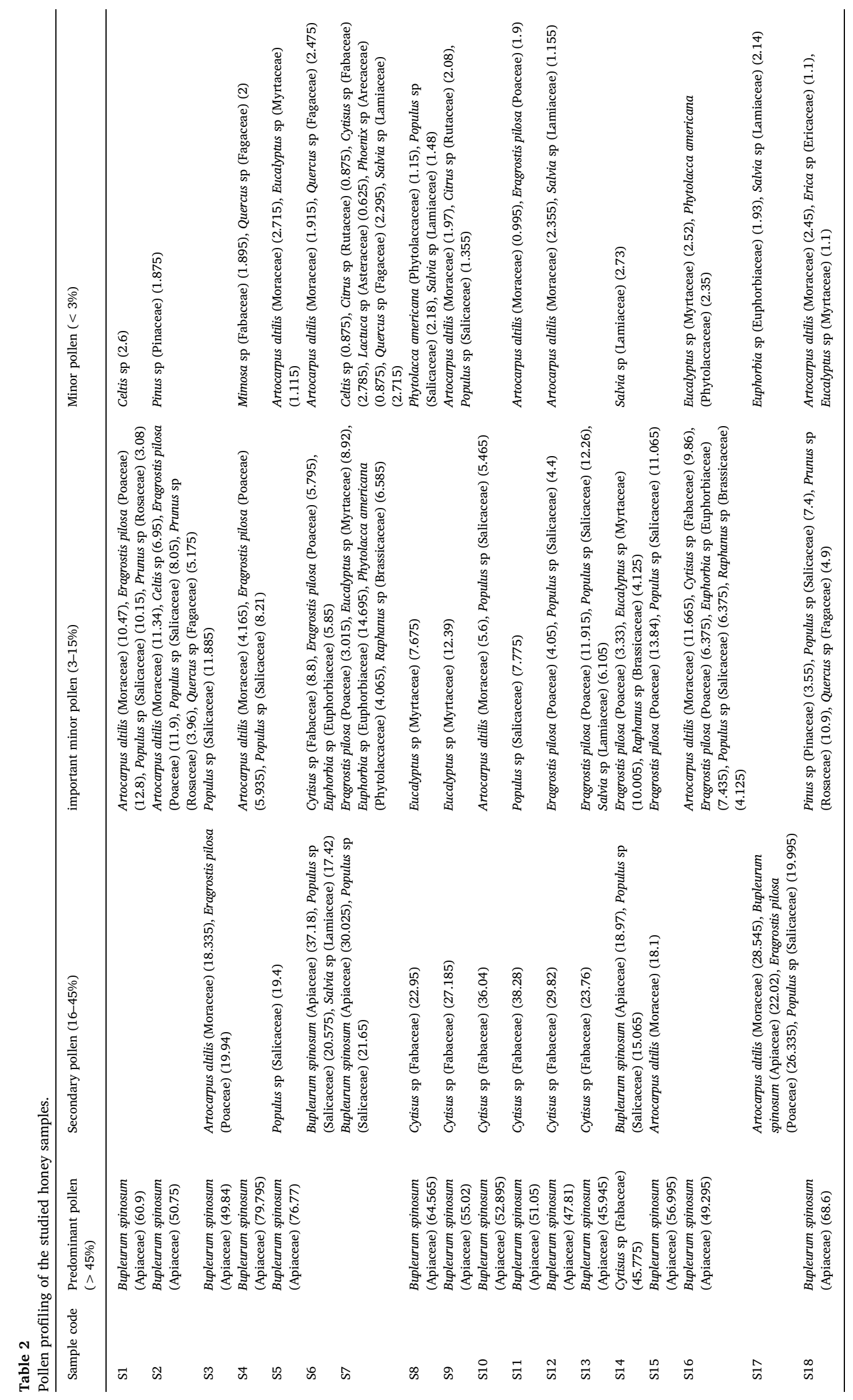




\subsection{Statistical tools}

To estimate the differences amongst the analysed samples regarding each of the assessed parameters, ANOVA, followed by a post hoc Tukey test was used and the means were considered to be significantly different when $p<0.05$.

The PCA was used, as a powerful multivariate analysis for scales reduction, to integrate the information provided by several parameters in few principal components (PC). Prior to each PCA running, the data was normalized by subtracting the mean value and dividing by the standard deviation of each of the given values. To run the PCA a MultBiplot64 was used on MATLAB R2017a.

\section{Results and discussion}

\subsection{Preliminary descriptive characterization}

Firstly, a descriptive approach was adopted for a preliminary characterization of the 18 honey samples. Table 2 shows their pollen analysis spectrum. Bupleurum spinosum pollen was the predominant species, exceeding $45 \%$, except for S6, S7, S14 and S17, presenting values of $37.18 \%, 30.02 \%, 18.97 \%$ and $28.54 \%$, respectively. Regardless being secondary pollen (16-45\%) in the four samples, Bupleurum spinosum was the most abundant except for S14, where Cytisus sp., was the predominant species (45.77\%), and S17 where it was third after Artocarpus altilis (28.54\%) and Eragrostis pilosa (26.33\%). Besides being predominant pollen in sample S14, the Cytisus sp. was the secondary pollen in 6 samples with values between $22.95 \%$ and $38.28 \%$ in S8 and S11, respectively. Other secondary pollen species were: Eragrostis pilosa (S3), Populus sp. (S5), and Artocarpus altilis (S15 and S17).

An overview of the pollen analysis applied previously to the samples of the same botanical origin (Elamine et al., 2018), revealed more contribution of $B$. spinosum pollen presenting an average of $62.50 \pm 8.66 \%$ compared to the samples of the current work $(51.02 \pm 16.11 \%)$. Besides this quantitative difference, some pollen species were only identified in one of the two groups, making a qualitative difference between them. Namely, Thymus sp., Opuntia sp., Phoenix sp., Olea sp., Epilobium sp., Cactus sp. and Acacia sp. were identified only in the samples of the previous study, while the current work was specifically characterized by the presence of Populus sp., Prunus sp., Quercus sp., Raphanus sp., Salvia sp., Euphorbia sp., Lactuca sp., Mimosa sp., Artocarpus altilis, Phytolacca sp., Pinus sp., Erica sp., Citrus sp., Celtis sp. and Cytisus sp. The effect of the mentioned differences on the assessed parameters will be discussed with details in the multivariate analysis section.

The studied physicochemical parameters are summarized in Table 3. The $\mathrm{pH}$ values ranged from 3.74 to 4.39 with an average value of $4.03 \pm 0.21$ considering the 18 samples. The same average can be seen in the previously analysed samples (previous season). The lactonic acidity varied also amongst the analysed samples between $8.00 \pm 1.49$ $\mathrm{mEq} / \mathrm{kg}$ and $16 \pm 0.86 \mathrm{mEq} / \mathrm{kg}$. The average values of the free and lactonic acidity $(20.28 \pm 6.36 \mathrm{mEq} / \mathrm{kg}-12.11 \pm 1.82 \mathrm{mEq} / \mathrm{kg})$ were slightly lower than those observed in the previous work $(25.70 \pm 6.46$ $\mathrm{mEq} / \mathrm{kg}$ and $16.58 \pm 1.40 \mathrm{mEq} / \mathrm{kg}$ ).

The ash content and the electrical conductivity were evaluated. A correlation between the two parameters is reported in addition to their correlation with the mineral composition of honey samples (Aazza, Lyoussi, Antunes, \& Miguel, 2013). The correlation can be seen by the fact that samples presenting low ash content had also low electrical conductivity, and vice versa. The lowest ash content percentage was $0.11 \pm 0.02 \%$, while the highest ash value was $0.32 \pm 0.03 \%$. For the electrical conductivity, the minimum and the maximum values, were $351.66 \pm 0.57 \mu \mathrm{s} / \mathrm{cm}$ and $900.33 \pm 3.05 \mu \mathrm{s} / \mathrm{cm}$, respectively. Both assessed parameters can be used, not only to predict the richness on mineral elements, and so its nutritional value (Ribeiro et al., 2014) but also for honey quality control purpose. According to the international
Table 3

Physicochemical characterization and sugar profile of the analysed honey samples.

\begin{tabular}{|c|c|c|c|c|}
\hline Assessed parameter (Unit) & Means & SD & Min & Max \\
\hline Ash content (\%) & 0.19 & 0.05 & 0.11 & 0.32 \\
\hline Water content $(\%)$ & 19.59 & 0.81 & 18.40 & 21.13 \\
\hline Electrical conductivity $\mu \mathrm{s} / \mathrm{cm}$ & 507.63 & 144.95 & 351.66 & 900.33 \\
\hline $\mathrm{pH}$ & 4.02 & 0.21 & 3.73 & 4.38 \\
\hline Free acidity $(\mathrm{mEq} / \mathrm{kg})$ & 20.28 & 6.36 & 8.40 & 32.80 \\
\hline Lactonic Acidity (mEq/kg) & 12.11 & 1.82 & 8.00 & 16.00 \\
\hline Total Acidity $(\mathrm{mEq} / \mathrm{kg})$ & 32.39 & 7.37 & 18.40 & 43.30 \\
\hline Diastase (Shad number) & 21.81 & 5.25 & 12.38 & 31.89 \\
\hline Melanoidins & 0.94 & 0.30 & 0.40 & 1.45 \\
\hline Colour (mmPfund) & 56.62 & 20.77 & 22.24 & 96.42 \\
\hline Fructose $(\mathrm{g} / 100 \mathrm{~g})$ & 37.43 & 2.42 & 33.52 & 41.83 \\
\hline Glucose $(\mathrm{g} / 100 \mathrm{~g})$ & 24.44 & 2.73 & 19.61 & 30.88 \\
\hline Fructose/Glucose Ratio & 1.52 & 0.22 & 1.12 & 2.13 \\
\hline Melebiose (g/100 g) & 2.66 & 0.96 & 0.62 & 4.31 \\
\hline Turanose (g/100 g) & 1.71 & 0.28 & 1.08 & 2.05 \\
\hline Maltose $(\mathrm{g} / 100 \mathrm{~g})$ & 1.56 & 0.63 & 0.34 & 3.03 \\
\hline Arabinose (g/100 g) & 1.44 & 0.67 & 0.33 & 2.44 \\
\hline Trehalose $(\mathrm{g} / 100 \mathrm{~g})$ & 0.88 & 0.39 & 0.41 & 2.03 \\
\hline Xylose $(\mathrm{g} / 100 \mathrm{~g})$ & 0.31 & 0.04 & 0.25 & 0.42 \\
\hline Melezitose (g/100 g) & 0.51 & 0.01 & 0.50 & 0.51 \\
\hline Sucrose $(\mathrm{g} / 100 \mathrm{~g})$ & - & - & - & - \\
\hline Rhamnose (g/100 g) & - & - & - & - \\
\hline Erlose $(\mathrm{g} / 100 \mathrm{~g})$ & - & - & - & - \\
\hline
\end{tabular}

Abbreviations: $\mathrm{SD}=$ standard deviation; Min $=$ Minimal; Max $=$ maximal.

legislation the ash content and the electrical conductivity are not allowed to be more than $800 \mu \mathrm{S} / \mathrm{cm}$ and $0.6 \%$, respectively in honey (European Union Directive (EU) (2014). Considering this, all analysed Zantaz honey samples were within the established values, except for one sample that had a value of $900.33 \pm 3.05 \mu \mathrm{s} / \mathrm{cm}$ for electrical conductivity. Furthermore, the comparison with the samples used in previous studies of our team showed no significant differences and the average value of the samples maintained almost the same: $0.20 \pm 0.05 \%$ and $507.63 \pm 144.95 \mu \mathrm{s} / \mathrm{cm}$ in comparison to the previous season $0.22 \pm 0.06 \%$ and $529.4 \pm 122.70 \mu \mathrm{s} / \mathrm{cm}$.

The diastase activity of the samples analysed in the present work was very similar to that observed on the previous harvest, and the average values were $22.80 \pm 5.55$ Shade units/g and $22.21 \pm 5.30$ Shade units/g, successively. Although, an important variability could be seen amongst the analysed samples with a minimum activity of $12.38 \pm 0.13$ Shade units $/ g$, and a maximum of $31.89 \pm 0.73$ Shade units/g, being all above the minimum value ( 8.0 Shade units/g) required for honey freshness confirmation by the European council (European Union Directive (EU), 2014).

The ripeness is another important step in the quality control of honey. Usually, the fast parameter used is the moisture content (Terrab, Díez, \& Heredia, 2002), which may be a factor favouring the growth and development of undesirable germs. Therefore, a maximum value was fixed to be $20 \%$ (European Union Directive (EU), 2014). In the present work eight of the analysed samples had moisture values between $20 \%$ and $21 \%$ (data not shown), and one sample presented a value of $21.13 \pm 0.23 \%$ being the maximum observed. The remaining samples did not exceed the $20 \%$, while the minimum value was $18.4 \pm 0.20 \%$.

Honey colour and melanoidins content are also important parameters in the characterization of honey samples. A well-established relationship is reported between the colour, bioactive compounds, and mineral content (Silva et al., 2016). Both parameters ranged in the analysed samples between $22.24 \pm 10.52 \mathrm{~mm}$ Pfund and $0.40 \pm 0.02$ $\mathrm{AU}$ as minimum values and maximum values of $96.42 \pm 6.99 \mathrm{~mm}$ Pfund and $1.45 \pm 0.03$ for colour and melanoidins respectively.

The results of the sugars profiling are summarized in Table 3. In all samples the fructose prevailed, and the average of the ratio fructose/ glucose was $1.56 \pm 0.25$ which is a usual value for honey (Anjos, 
Table 4

Mineral content of honey samples.

\begin{tabular}{|c|c|c|c|c|c|c|c|c|}
\hline & {$[\mathrm{K}] \mathrm{mg} / \mathrm{kg}$} & [Ca] mg/kg & [Na] mg/kg & {$[\mathrm{Mg}] \mathrm{mg} / \mathrm{kg}$} & {$[\mathrm{Fe}] \mathrm{mg} / \mathrm{kg}$} & {$[\mathrm{Cu}] \mathrm{mg} / \mathrm{kg}$} & {$[\mathrm{Mn}] \mathrm{mg} / \mathrm{kg}$} & [Zn] $\mathrm{mg} / \mathrm{kg}$ \\
\hline S1 & $566.30 \pm 3.18^{f}$ & $189.95 \pm 1.21^{\mathrm{b}}$ & $44.63 \pm 0.41^{\mathrm{k}}$ & $32.14 \pm 0.45^{\mathrm{def}}$ & $15.50 \pm 0.06^{\mathrm{b}}$ & $0.92 \pm 0.002^{\mathrm{j}}$ & $0.96 \pm 0.001^{\mathrm{d}}$ & $0.41 \pm 0.008^{\mathrm{k}}$ \\
\hline S2 & $679.34 \pm 3.40^{\mathrm{e}}$ & $170.73 \pm 7.62^{\text {cde }}$ & $77.69 \pm 0.56^{c}$ & $52.80 \pm 1.02^{\mathrm{a}}$ & $18.22 \pm 0.21^{\mathrm{a}}$ & $1.67 \pm 0.005^{\mathrm{d}}$ & $1.12 \pm 0.015^{\mathrm{b}}$ & $0.86 \pm 0.011^{\mathrm{f}}$ \\
\hline S3 & $702.39 \pm 6.87^{\mathrm{e}}$ & $221.12 \pm 17.72^{\mathrm{a}}$ & $39.82 \pm 0.30^{1}$ & $34.69 \pm 0.62^{\mathrm{cd}}$ & $9.41 \pm 0.13^{g}$ & $1.62 \pm 0.015^{\mathrm{de}}$ & $1.16 \pm 0.003^{\mathrm{a}}$ & $0.69 \pm 0.015^{\mathrm{i}}$ \\
\hline S4 & $492.35 \pm 2.04^{g}$ & $124.15 \pm 1.41^{\mathrm{ij}}$ & $38.39 \pm 0.05^{\mathrm{m}}$ & $26.98 \pm 0.98^{g h}$ & $11.93 \pm 0.19^{\mathrm{e}}$ & $0.89 \pm 0.022^{j}$ & $0.75 \pm 0.014^{\mathrm{i}}$ & $0.36 \pm 0.003^{1}$ \\
\hline S5 & $448.50 \pm 2.03^{g h}$ & $138.78 \pm 3.22^{h i}$ & $64.13 \pm 0.25^{\mathrm{e}}$ & $31.89 \pm 0.55^{\mathrm{def}}$ & $11.55 \pm 0.17^{\mathrm{ef}}$ & $1.02 \pm 0.007^{\mathrm{i}}$ & $0.69 \pm 0.007^{\mathrm{j}}$ & $0.26 \pm 0.008^{\mathrm{n}}$ \\
\hline S6 & $594.02 \pm 1.15^{f}$ & $104.15 \pm 2.43^{\mathrm{kl}}$ & $64.97 \pm 0.12^{\mathrm{e}}$ & $20.94 \pm 0.57^{\mathrm{i}}$ & $6.78 \pm 0.054^{j}$ & $1.06 \pm 0.002^{\mathrm{i}}$ & $0.46 \pm 0.005^{\mathrm{m}}$ & $0.44 \pm 0.004^{\mathrm{k}}$ \\
\hline S7 & $558.61 \pm 1.45^{\mathrm{f}}$ & $103.72 \pm 3.67^{\mathrm{kl}}$ & $58.04 \pm 0.04^{\mathrm{h}}$ & $27.78 \pm 0.61^{\mathrm{gh}}$ & $6.72 \pm 0.10^{\mathrm{j}}$ & $1.39 \pm 0.013^{f}$ & $0.51 \pm 0.001^{1}$ & $1.29 \pm 0.016^{\mathrm{c}}$ \\
\hline S8 & $755.55 \pm 0.95^{\mathrm{d}}$ & $124.41 \pm 2.52^{\mathrm{ij}}$ & $90.90 \pm 0.26^{\mathrm{b}}$ & $24.25 \pm 0.09^{\mathrm{hi}}$ & $7.61 \pm 0.01^{\mathrm{i}}$ & $1.07 \pm 0.008^{i}$ & $0.67 \pm 0.007^{j}$ & $1.72 \pm 0.002^{\mathrm{b}}$ \\
\hline S9 & $1177.47 \pm 18.29^{\mathrm{a}}$ & $173.79 \pm 4.71^{\mathrm{cd}}$ & $59.59 \pm 0.26^{g}$ & $50.22 \pm 1.006^{\mathrm{a}}$ & $15.61 \pm 0.08^{\mathrm{b}}$ & $1.95 \pm 0.019^{\mathrm{b}}$ & $0.87 \pm 0.008^{\mathrm{f}}$ & $0.81 \pm 0.006^{g}$ \\
\hline S10 & $429.15 \pm 2.31^{\mathrm{h}}$ & $153.43 \pm 1.88^{\mathrm{fgh}}$ & $51.23 \pm 0.48^{\mathrm{i}}$ & $24.35 \pm 1.89^{\mathrm{hi}}$ & $14.01 \pm 0.12^{\mathrm{d}}$ & $1.061 \pm 0.003^{\mathrm{i}}$ & $0.51 \pm 0.004^{1}$ & $0.42 \pm 0.004^{\mathrm{k}}$ \\
\hline S11 & $584.34 \pm 0.94^{\mathrm{f}}$ & $169.82 \pm 0.98^{\mathrm{cde}}$ & $49.33 \pm 0.19^{j}$ & $29.92 \pm 0.92^{\mathrm{efg}}$ & $18.23 \pm 0.15^{\mathrm{a}}$ & $1.80 \pm 0.023^{\mathrm{c}}$ & $0.88 \pm 0.012^{\mathrm{f}}$ & $0.88 \pm 0.014^{\mathrm{f}}$ \\
\hline S12 & $468.73 \pm 3.27^{g h}$ & $180.08 \pm 2.14^{\mathrm{bc}}$ & $50.02 \pm 0.20^{\mathrm{j}}$ & $24.21 \pm 0.09^{\mathrm{hi}}$ & $15.59 \pm 0.15^{\mathrm{b}}$ & $1.57 \pm 0.009^{\mathrm{e}}$ & $0.84 \pm 0.005^{g}$ & $0.32 \pm 0.014^{\mathrm{m}}$ \\
\hline S13 & $774.69 \pm 4.18^{\mathrm{d}}$ & $158.25 \pm 2.06^{\mathrm{efg}}$ & $77.20 \pm 0.22^{c}$ & $44.71 \pm 2.41^{\mathrm{b}}$ & $14.52 \pm 0.10^{c}$ & $0.89 \pm 0.010^{\mathrm{j}}$ & $0.79 \pm 0.003^{\mathrm{h}}$ & $1.02 \pm 0.010^{\mathrm{d}}$ \\
\hline S14 & $1013.45 \pm 5.64^{\mathrm{b}}$ & $94.18 \pm 1.95^{1}$ & $163.38 \pm 1.22^{\mathrm{a}}$ & $36.77 \pm 1.44^{\mathrm{c}}$ & $7.84 \pm 0.05^{\mathrm{i}}$ & $6.43 \pm 0.073^{\mathrm{a}}$ & $0.74 \pm 0.002^{\mathrm{i}}$ & $2.02 \pm 0.010^{\mathrm{a}}$ \\
\hline S15 & $694.71 \pm 39.56^{\mathrm{e}}$ & $142.85 \pm 0.89^{g h}$ & $44.01 \pm 0.18^{\mathrm{k}}$ & $30.31 \pm 1.14^{\mathrm{efg}}$ & $11.52 \pm 0.06^{\mathrm{f}}$ & $1.29 \pm 0.005 \mathrm{~g}$ & $0.93 \pm 0.006^{\mathrm{e}}$ & $0.35 \pm 0.006^{\mathrm{lm}}$ \\
\hline S16 & $704.48 \pm 5.23^{\mathrm{e}}$ & $94.65 \pm 1.66^{1}$ & $62.31 \pm 0.19^{d}$ & $32.80 \pm 0.95^{\mathrm{de}}$ & $8.75 \pm 0.12^{\mathrm{h}}$ & $1.69 \pm 0.014^{\mathrm{d}}$ & $0.62 \pm 0.002^{\mathrm{k}}$ & $0.94 \pm 0.005^{\mathrm{e}}$ \\
\hline S17 & $885.73 \pm 48.43^{c}$ & $115.32 \pm 1.21^{\mathrm{jk}}$ & $74.28 \pm 0.15^{\mathrm{d}}$ & $37.29 \pm 1.71^{\mathrm{c}}$ & $11.90 \pm 0.09^{\mathrm{ef}}$ & $1.08 \pm 0.008^{\mathrm{i}}$ & $0.62 \pm 0.001^{\mathrm{k}}$ & $0.73 \pm 0.013^{h}$ \\
\hline S18 & $554.21 \pm 2.18^{f}$ & $159.95 \pm 0.43^{\mathrm{def}}$ & $57.10 \pm 0.07^{\mathrm{h}}$ & $28.78 \pm 2.38^{\mathrm{fg}}$ & $17.98 \pm 0.17^{\mathrm{a}}$ & $1.18 \pm 0.053^{\mathrm{h}}$ & $1.07 \pm 0.010^{c}$ & $0.50 \pm 0.006^{j}$ \\
\hline
\end{tabular}

Values in the same column followed by the same letter are not significant different $(\mathrm{p}<0.05)$ by the Tukey's multiple range test.

Campos, Ruiz, \& Antunes, 2015b). The ratio variability ranged from a minimum of 1.13 to a maximum of 2.13. In terms of abundance, after fructose and glucose, the evaluated sugars were classified as follow: melebiose, turanose, maltose, arabinose, trehalose and xylose. While melezitose was detected in two samples, ramnose, erlose, and sucrose were below $0.2 \%$, the detection threshold. In the samples of the previous study, the ratio fructose/glucose was $1.48 \pm 0.17$ ( $\mathrm{min}=1.25$ and $\max =1.74$ ), lower than the current samples. Other differences involve, mainly, the big reduction in the melezitose content from $2.00 \pm 0.30 \mathrm{~g} / 100 \mathrm{~g}$ honey, to be detected only in two samples. The relationship between this variability and the one of the pollen analyses will be probed in the multivariate analysis section.

When analysing the mineral content of Zantaz honeys, potassium prevailed in all samples, as reported in literature (Silva et al., 2016), followed by the calcium, and in a third position the sodium (Table 4). While the magnesium and iron occupied the forth and the fifth places, cupper, manganese and zinc were present at very low levels with values equal or below $2 \mathrm{mg} / \mathrm{kg}$, except one sample which presented an amount of $6.43 \pm 0.073 \mathrm{mg} / \mathrm{kg}$ cupper. Sample S9 presented the highest amount of potassium, calcium and iron, and the second highest amount of magnesium with values of $1177.47 \pm 18.29 \mathrm{mg} / \mathrm{kg}$, $50.22 \pm 1.006 \mathrm{mg} / \mathrm{kg}, 15.61 \pm 0.08 \mathrm{mg} / \mathrm{kg}$, and $50.22 \pm 1.006 \mathrm{mg} /$ $\mathrm{kg}$, successively. The lowest amounts were observed in honey samples S5 $\quad(448.50 \pm 2.03 \mathrm{mg} / \mathrm{kg}), \quad \mathrm{S} 14 \quad(94.18 \pm 1.95 \mathrm{mg} / \mathrm{kg}), \quad$ S8 $(7.61 \pm 0.01 \mathrm{mg} / \mathrm{kg})$ and $\mathrm{S} 6(20.94 \pm 0.57 \mathrm{mg} / \mathrm{kg})$, successively for potassium, calcium, iron and magnesium. For the sodium, the minimum value was $38.39 \pm 0.05 \mathrm{mg} / \mathrm{kg}$ observed in sample $\mathrm{S} 4$, while the maximum value was $163.38 \pm 1.22 \mathrm{mg} / \mathrm{kg}$ in sample S14. In overall, the mineral content, based on the assessed elements, ranged between $0.067 \%$ (S10) and $0.148 \%$ (S9), being within the reported values (0.04\%-0.2\%) (Silva et al., 2016).

\subsection{Multivariate analysis}

For honey types with well-established monoflorality percentage, authors declared the importance of identified pollen species in shaping the final characteristics of honey samples (Oddo \& Piro, 2004). An example is that of lavender honey (Estevinho et al., 2016; Anjos, Santos, Paixão, \& Estevinho, 2018), for which authors, after confirming that all analysed samples presented lavender pollen more than the monoflorality threshold (15\%), found different clustering profiles using the pollen analysis or the physicochemical characteristics. Furthermore, when analysing the differences between the established clusters, the same authors found no significant contribution of lavender pollen, highlighting so the importance of other pollens in shaping the physicochemical features of a honey.

From the previous reference (Estevinho et al., 2016), a similar behaviour was expected to be seen in the case of Zantaz honey samples characterized by the prevalence of Bupleurum spinosum pollen. This expectation could be seen clearly considering Figs. 1 and 2, where specific pollen species correlate differently the assessed parameters. In other words, if we consider two honey samples presenting the same amount of $B$. spinosum pollen, but different secondary pollen species, both samples will share the characteristics provided by the main nectar, and other distinguished features matching other participating nectars. From this point of view, and as the pollen species varies greatly amongst the analysed samples, the determination of monoflorality threshold of Zantaz honey will not be a trivial task unless the maximum of parameters is considered, as well as the sensorial analysis.

Fig. 1 illustrates the distribution of the 30 Zantaz honey samples belonging to both seasons based on their melissopalynological and physicochemical analyses. To retain a good representability of the given data three components were used for plotting. The three first components represented $23.97 \%, 20.78 \%$ and $15.87 \%$ respectively. Considering the two first components (Fig. 1 (a)), a reasonable discrimination was seen between the 12 samples of the previous work (black circles) and the 18 honey samples of the current contribution (blue squares).

The samples of the previous season were characterized by the presence of more B. spinosum and Phoenix. ssp pollen, in comparison with the other samples, making them, based on the seen positive correlation, more acidic and darker. The current work samples presented, mainly, more Eucalyptus sp., Euphorbia sp., Populus sp., and so presented the opposite features: high $\mathrm{pH}$ values and light colour. A sub-group of those last samples, located in the bottom of the plot, was characterized by more Eragostis sp. and Artocarpus sp. Pollens and was characterized by low ash content and electrical conductivity.

Employing the first and the third PCs (Fig. 1 (b)), the conserved information did not allow the same discrimination level as in Fig. 1 (a), although it conserved the same correlation between the presence of pollen species and confirmed that there are a higher similarity between samples with higher amounts of Eragostis and Artocarpus pollens, which were significantly different from those with higher amount of $B$. spinosum pollen.

To evaluate a possible effect of pollen variability on sugar content, another PCA was made using a data matrix fusing both parameters. Also, to improve the conservation of the given data, three components were employed. Considering the first and the second PCs (Fig. 1 (c)), 

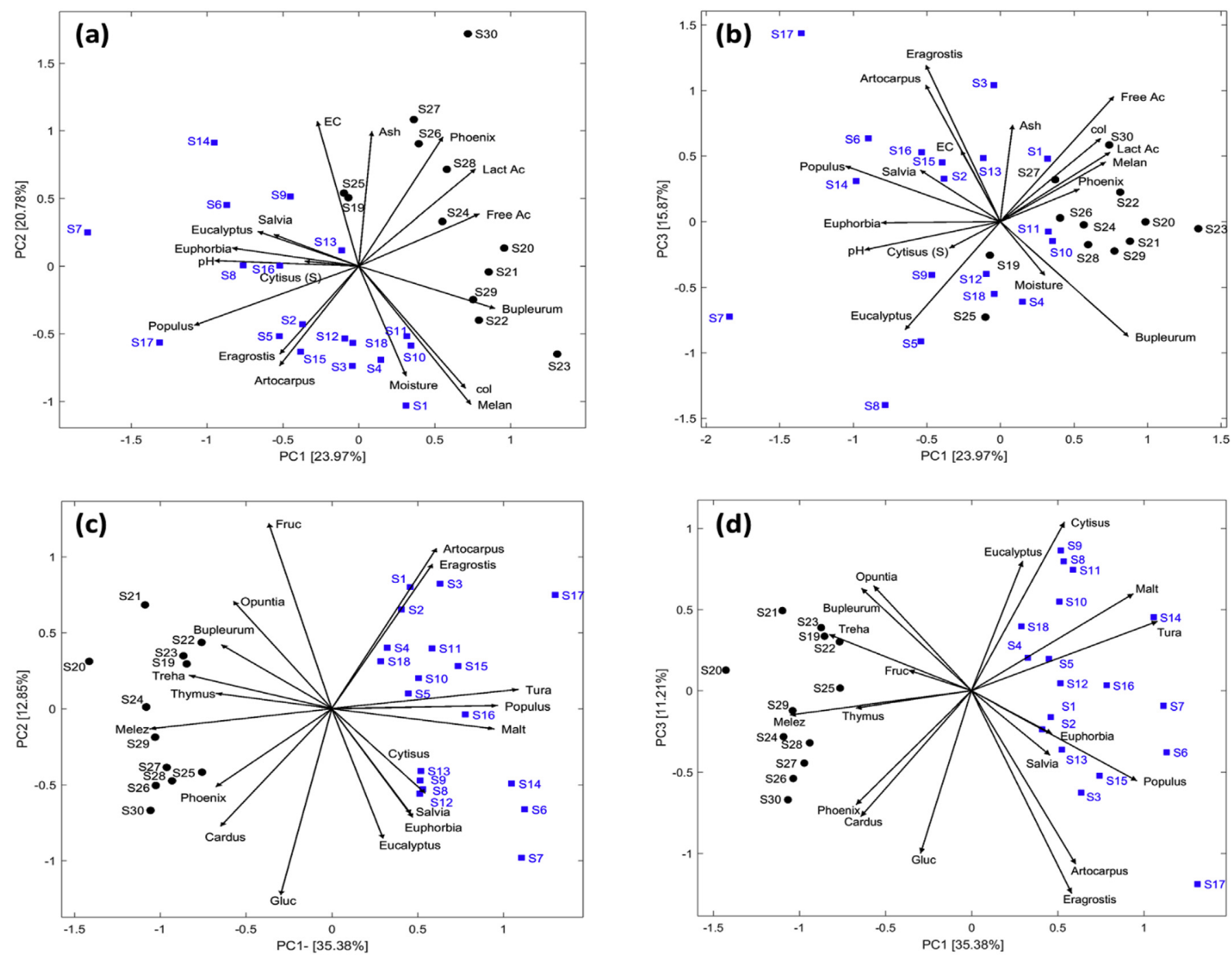

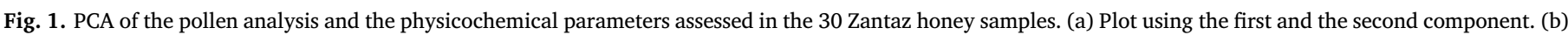
Plot using the first and the third components. (c) Plot using the first and the second component. (d) Plot using the first and the third components.
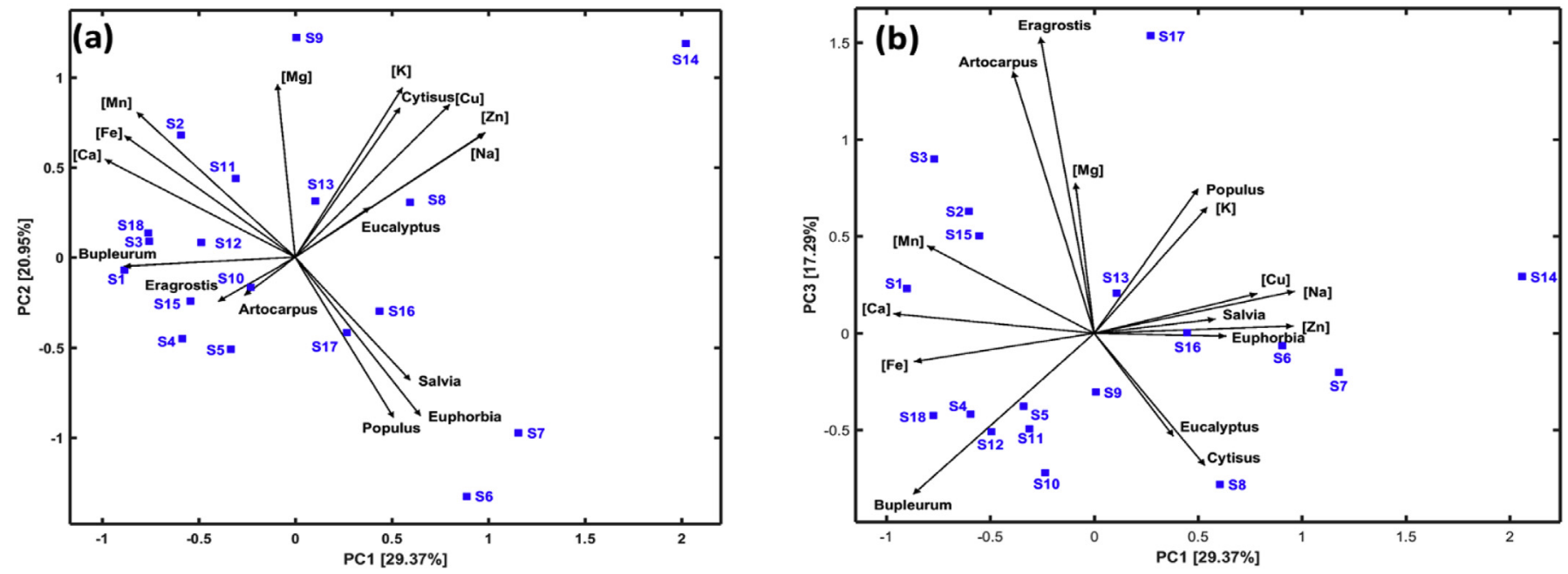

Fig. 2. PCA of the pollen analysis and the mineral content of the 18 Zantaz honey samples. (a) Plot using the first and the second component. (b) Plot using the first and the third components. 
which explained $35.38 \%$ and $12.85 \%$ respectively, the samples of the two seasons were perfectly discriminated from each other by the PC1. The 12 samples of the previous works were characterized by the prevalence of B. spinosum, Opuntia sp., Thymus sp., Phoenix sp. and Cardus sp. pollens, and occupied the negative part of PC1. This pollen prevalence characterized the samples by higher levels in terms of trehalose and melezitose. In the 18 honey samples characterized in the present work, the Artocarpus sp., Eragostis sp., Populus sp., Salvia sp., Euphorbia sp. and Eucalyptus sp. pollens prevailed, and the samples presented higher amount of turanose and maltose. Considering the fructose and the glucose, they correlated oppositely, as observed by other authors (Anjos et al., 2015b) the PC2, presenting, so little participation to the mentioned discrimination.

Besides being a good tool for the discrimination of the geographical origin, the mineral content can also suggest the botanical origin (Pasquini et al., 2014). Therefore, a PCA was also employed to illustrate the relationship between the pollen species and the evaluated minerals. As the mineral content was only made for the 18 samples of the present work, their data was used for PCA, and the first three components conserved a sum of $67.61 \%$ of the given data. In overall no clear clustering could be seen amongst the analysed samples (Fig. 2 (a)), except the discrimination of samples S14, presenting high percentage of Cytisus sp. pollen and high levels of $\mathrm{Cu}, \mathrm{Zn}, \mathrm{Na}$ and $\mathrm{K}$. In addition, honey samples S6 and S7 were discriminated by their high amounts of Salvia sp., Euphorbia sp. and Popolus sp. pollens which were linked to the prevalence of $\mathrm{Cu}, \mathrm{Zn}$ and $\mathrm{Na}$. the presence of high amounts of $B$. spinosum pollen was linked to higher amounts of $\mathrm{Ca}, \mathrm{Fe}$ and $\mathrm{Mn}$.

When PC1 was plotted against PC3 (Fig. 2 (b)), the same observation of Fig. 2 (a) were made, as the first PC was the most representative in terms of data conservation. Furthermore, the presence of Eragostis sp. and Artocapus sp. was linked to the amount of $\mathrm{Mg}$ and the three variables were highly represented by the third PC, which explained $17.29 \%$ from the given data. Also, the relation between Salvia sp. and Euphorbia sp. and $\mathrm{Cu}, \mathrm{Na}$ and $\mathrm{Zn}$ became clearer.

To further understand how the presence of B. spinosum pollen, in addition to the other major represented pollen species, shape the final characteristics of Zantaz honey, a PCA integrating all the assessed physicochemical parameters was employed. Prior to running PCA, the data was subjected to the standardization. As the 18 samples of the present work were more characterized then those of the previous work, they were chosen to be used for the next section. The output is illustrated in Fig. 3 (a).

The first two PCs explaining $40.02 \%$ and $21.74 \%$, successively of the given data, were used for plotting. Considering PC1, two groups could be distinguished: a group labelled as black squares presenting an average value of $58 \pm 11.24 \%$ of $B$. spinosum pollen, and a second one, labelled in blue circles, presented an average of $40 \pm 15.98 \%$. three samples of this group were above the average of $B$. spinosum pollen percentage and were misplaced in the left side of the plot. The samples were, namely, S8, S9 and S16, and shared with sample S7 the presence of Eucalyptus pollen. The presence of Eucalyptus sp. pollen is linked to the production of light coloured honey, which may explain the divergence seen in the three mentioned samples compared to the remaining samples.

The observation of the variables plot showed on the onset of Fig. 3 (a) confirmed the conclusion of PCA described previously (Figs. 1 and 2): The presence of $B$. spinosum pollen correlates positively the values of colour, melanoidins, moisture, iron, manganese and calcium. However, the data concerning the sugar must be confirmed in previous work compared samples with higher amount of $B$. spinosum pollen and low or quite null percentage of these pollens.

To estimate the significance of the difference observed after the use of physicochemical parameters, the means of the major represented pollen species were compared between the two obtained groups, and the results were illustrated in Fig. 3(b). B. spinosum pollen showed to play an important role in this discrimination, and the difference was significant at $\mathrm{p}<0.05$. Another important feature is the prevalence of the Cystus sp. and Populus sp. pollens in the groups presenting low levels of $B$. spinosum pollen, although the difference was not significant.
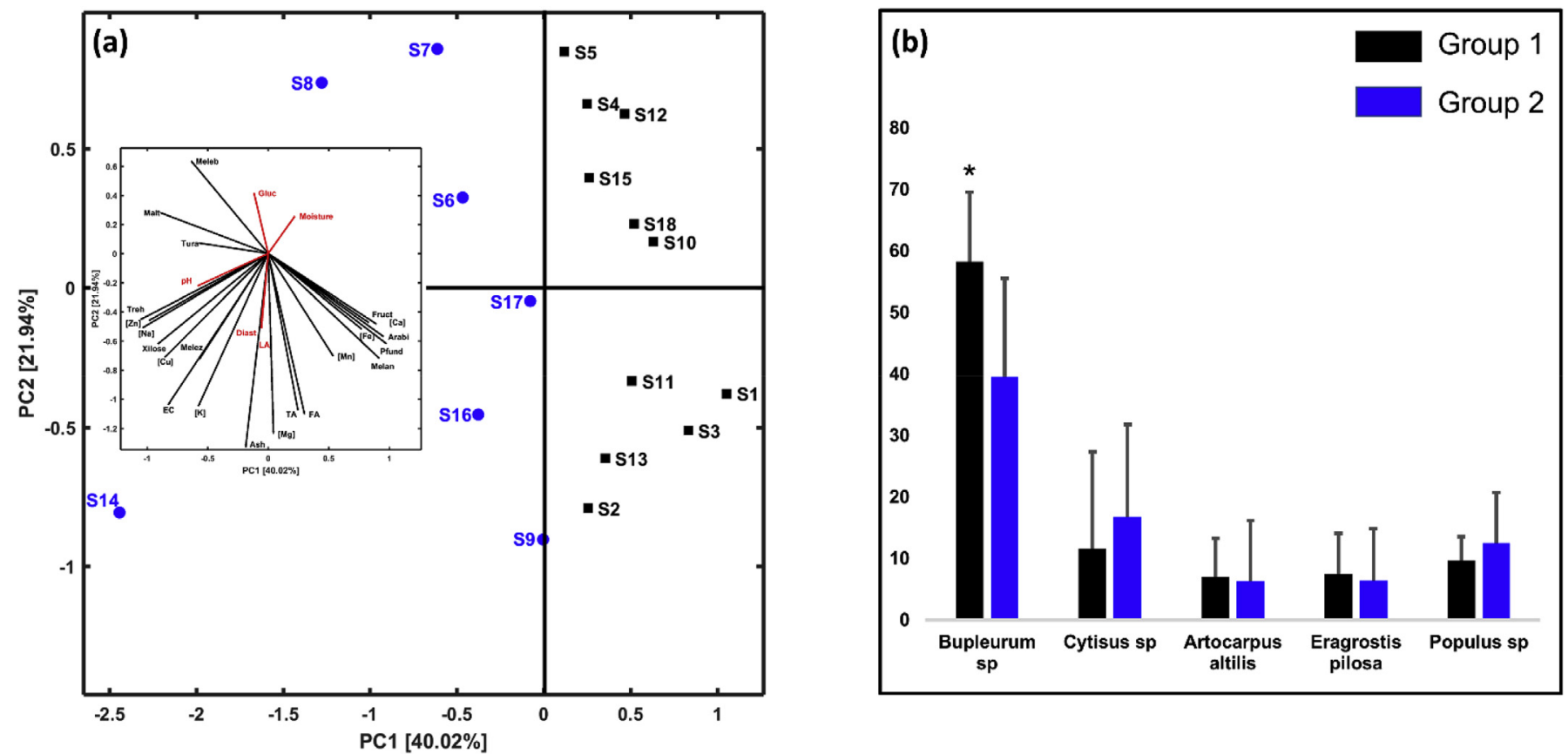

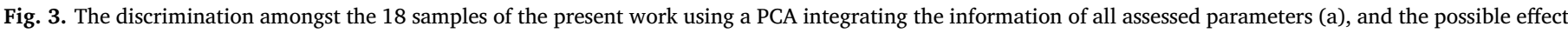

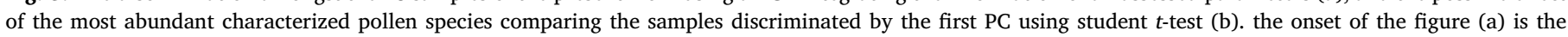

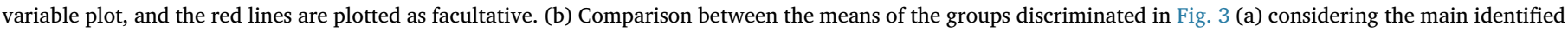
pollen species * $\mathrm{P}<0.05$. (For interpretation of the references to colour in this figure legend, the reader is referred to the Web version of this article.) 


\section{Conclusion}

In this second contribution to the characterization of the Moroccan Zantaz honey, known by the predominance of Bupleurum spinosum pollen, $83.33 \%$ of the analysed samples presented more than $45 \%$ of $B$. spinosum pollen, which is the general monofloral threshold for honey monoflorality declaration. Besides the pollen identification, the analysis concerned mainly the sugar and mineral profiling in addition to a panel of physicochemical parameters used for honey quality control. The results showed no important aberrant values in comparison to the previous study published by our team. While comparing the data of honey samples belonging to both seasons, an attempt to understand the relationship between the identified pollen species and the routinely assessed physicochemical parameters was performed using the clustering ability of PCA. The presence of Bupleurum spinosum pollen was correlated to the levels of acidity, colour intensity, trehalose, melezitose, $\mathrm{Ca}, \mathrm{Fe}$ and $\mathrm{Mn}$.

When integrating all assessed physicochemical parameters, a PCA conserving $61.96 \%$ of the given data allowed discriminating the two groups of honey samples. The samples of the first group presented a mean of $58 \pm 11.24 \%$ in terms of B.spinosum pollen and was significantly higher $(\mathrm{p}<0.05)$ than the mean percentage obtained for the second group $(40 \pm 15.98 \%)$. No significant difference was seen in the case of other pollen species, suggesting the importance of $B$. spinosum nectar in shaping the acquired features of Zantaz honey samples. Considering the means of the two groups $(58 \pm 11.24 \%$ and $40 \pm 15.98 \%$ ), one can speculate that a Zantaz honey sample obey, at least, the general monoflorality threshold of $45 \%$, though, a determinant conclusion can be made only after a detailed sensorial study.

\section{Declarations of interest}

None.

\section{Acknowledgments}

The authors wish to acknowledge the financial support provided by the Portuguese National Funding Agency for Science, Research and Technology (Fundação para a Ciência e a Tecnologia - FCT; Portugal), under the projects UID/BIA/04050/2013, UID/BIA/04325/ 2013-MEDTBIO, and UID/Multi/04326/2013.

Centro de Estudos Florestais is a Research Unit funded by Fundação para a Ciência e a Tecnologia within UID/AGR/00239/2019.

The authors thank to Conceição Vitorino for their support with sugar analytical procedures.

\section{References}

Aazza, S., Lyoussi, B., Antunes, D., \& Miguel, M. G. (2013). Physicochemical characterization and antioxidant activity of commercial Portuguese honeys. Journal of Food Science, 78(8), C1159-C1165. https://doi.org/10.1111/1750-3841.12201.

Anjos, O., Campos, M. G., Ruiz, P. C., \& Antunes, P. (2015b). Application of FTIR-ATR spectroscopy to the quantification of sugar in honey. Food Chemistry, 169, 218-223. https://doi.org/10.1016/j.foodchem.2014.07.138.

Anjos, O., Iglesias, C., Peres, F., Martínez, J., García, Á., \& Taboada, J. (2015a). Neura networks applied to discriminate botanical origin of honeys. Food Chemistry, 175, 128-136. https://doi.org/10.1016/j.foodchem.2014.11.121.

Anjos, O., Santos, A. J. A., Paixão, V., \& Estevinho, L. M. (2018). Physicochemical characterization of Lavandula spp. honey with FT-Raman spectroscopy. Talanta, 178, 43-48. https://doi.org/10.1016/j.talanta.2017.08.099.

Bertacchini, L., Cocchi, M., Li Vigni, M., Marchetti, A., Salvatore, E., Sighinolfi, S., et al. (2013). (1st ed.). The impact of chemometrics on food traceabilityVol. 28Data Handling in Science and Technology. Copyright (C) 2013 Elsevier B.V. All rights reserved https://doi.org/10.1016/B978-0-444-59528-7.00010-7.

Bevilacqua, M., Bucci, R., Magrì, A. D., Magrì, A. L., \& Nescatelli, R. (2013).
Chemometrics in food chemistry. Data Handling in Science and Technology, 28, 171-233. https://doi.org/10.1016/B978-0-444-59528-7.00005-3.

Bogdanov, S. (1997). Harmonised methods of the international honey comission. International honey comissionhttp://www.bee-hexagon.net/en/network.htm.

Bogdanov, S., Ruoff, K., \& Oddo, L. P. (2004). Physicochemical methods for the characterisation of unifloral honeys: A review. Apidologie, 35. https://doi.org/10.1051/ apido:2004047 article.

Briandet, R., Kemsley, E. K., \& Wilson, R. H. (1996). Discrimination of arabica and robusta in instant coffee by fourier transform infrared spectroscopy and chemometrics. Journal of Agricultural and Food Chemistry, 44, 170-174. https://doi.org/10.1021/ jf950305a.

Brudzynski, K., \& Miotto, D. (2011). The recognition of high molecular weight melanoidins as the main components responsible for radical-scavenging capacity of unheated and heat-treated Canadian honeys. Food Chemistry, 125(2), 570-575. https:// doi.org/10.1016/j.foodchem.2010.09.049.

Corbella, E., \& Cozzolino, D. (2006). Classification of the floral origin of Uruguayan honeys by chemical and physical characteristics combined with chemometrics. Food Science and Technology, 39(5), 534-539. https://doi.org/10.1016/j.lwt.2005.03.011.

Devillers, J., Morlot, M., Pham-Delègue, M. H., \& Doré, J. C. (2004). Classification of monofloral honeys based on their quality control data. Food Chemistry, 86(2), 305-312. https://doi.org/10.1016/j.foodchem.2003.09.029.

Elamine, Y., Aazza, S., Lyoussi, B., Dulce Antunes, M., Estevinho, L. M., Anjos, O., ... Miguel, M. G. (2018). Preliminary characterization of a Moroccan honey with a predominance of Bupleurum spinosum pollen. Journal of Apicultural Research, 57(1), 153-165. https://doi.org/10.1080/00218839.2016.1265759.

Estevinho, L. M., Chambó, E. D., Pereira, A. P. R., De Carvalho, C. A. L., \& De Alencar Arnaut De Toledo, V. (2016). Characterization of lavandula spp. honey using multivariate techniques. PLoS One, 11(9), 1-15. https://doi.org/10.1371/journal.pone. 0162206.

European Union Directive (EU) (2014). Council directive 2001/110 relating to honey. Official Journal of the European Communities, 16, 1-12 December 2001.

Karabagias, I. K., Louppis, A. P., Karabournioti, S., Kontakos, S., Papastephanou, C., \& Kontominas, M. G. (2017a). Characterization and classification of commercial thyme honeys produced in specific Mediterranean countries according to geographical origin, using physicochemical parameter values and mineral content in combination with chemometrics. European Food Research and Technology, 243(5), 889-900. https://doi.org/10.1007/s00217-016-2803-0.

Karabagias, I. K., Louppis, A. P., Karabournioti, S., Kontakos, S., Papastephanou, C., \& Kontominas, M. G. (2017b). Characterization and geographical discrimination of commercial Citrus spp. honeys produced in different Mediterranean countries based on minerals, volatile compounds and physicochemical parameters, using chemometrics. Food Chemistry, Vol. 217Elsevier Ltdhttps://doi.org/10.1016/j.foodchem.2016.08.124.

Louveaux, J., Maurizio, A., \& Vorwohl, G. (1978). Methods of melissopalynology. Bee World, 5(3), 139-153. https://doi.org/10.1080/0005772X.1978.11097714.

Naab, O. A., Tamame, M. A., \& Caccavari, M. A. (2008). Palynological and physicochemical characteristics of three unifloral honey types from central Argentina. Spanish Journal of Agricultural Research, 6(4), 566-576.

Oddo, L. P., \& Piro, R. (2004). Main european unifloral honeys: Descriptive sheets. Apidologie, 35, 38-81. https://doi.org/10.1051/apido:2004049.

Pasquini, B., Goodarzi, M., Orlandini, S., Beretta, G., Furlanetto, S., \& Dejaegher, B. (2014). Geographical characterisation of honeys according to their mineral content and antioxidant activity using a chemometric approach. International Journal of Food Science and Technology, 49(5), 1351-1359. https://doi.org/10.1111/ijfs.12436.

Pestorić, M., Šimurina, O., Filipčev, B., Jambrec, D., Belović, M., Mišan, A., et al. (2015) Relationship of physicochemical characteristics with sensory profile of cookies enriched with medicinal herbs. International Journal of Food Properties, 18(12), 2699-2712. https://doi.org/10.1080/10942912.2015.1004586.

Piana, M. L., Oddo, L. P., Bentabol, A., Bruneau, E., Bogdanov, S., \& Declerck, C. G. (2004). Sensory analysis applied to honey: State of the art. Apidologie, 35. https://doi. org/10.1051/apido:2004048 article.

Ribeiro, R.de O. R., Mársico, E. T., De Jesus, E. F. O., da Silva Carneiro, C., Júnior, C. A C., de Almeida, E., et al. (2014). Determination of trace elements in honey from different regions in rio de Janeiro state (Brazil) by total reflection X-ray fluorescence. Journal of Food Science, 79(4), 738-742. https://doi.org/10.1111/1750-3841.12363.

Silva, P. M. D., Gauche, C., Gonzaga, L. V., Costa, A. C. O., \& Fett, R. (2016). Honey: Chemical composition, stability and authenticity. Food Chemistry, 196, 309-323. https://doi.org/10.1016/j.foodchem.2015.09.051.

Terrab, A., Díez, M. J., \& Heredia, F. J. (2002). Characterisation of Moroccan unifloral honeys by their physicochemical characteristics. Food Chemistry, 79(3), 373-379. https://doi.org/10.1016/S0308-8146(02)00189-9.

Wang, J., Xue, X., Du, X., Cheng, N., Chen, L., Zhao, J., et al. (2014). Identification of Acacia honey adulteration with rape honey using Liquid chromatography-electrochemical detection and chemometrics. Food Analytical Methods, 7(10), 2003-2012. https://doi.org/10.1007/s12161-014-9833-7.

Zhao, H., Cheng, N., Zhang, I., Sun, Z., Zhou, W., Wang, Y., et al. (2018). The effects of different thermal treatments on amino acid contents and chemometric-based identification of overheated honey. Lebensmittel-Wissenschaft und -Technologie, 96, 133-139. https://doi.org/10.1016/j.lwt.2018.05.004. 